\title{
Application of CRISPR-Cas9 gene editing for congenital heart disease
}

\author{
Heeyoung Seok, PhD ${ }^{1}$, Rui Deng, $\mathrm{MD}^{2,3}$, Douglas B. Cowan, PhD ${ }^{2,3}$, Da-Zhi Wang, PhD, FAHA ${ }^{2,3}$ \\ ${ }^{1}$ Department of Life Sciences, Korea University, Seoul, Korea; ${ }^{2}$ Department of Cardiology, Boston Children's Hospital, Boston, MA, USA; ${ }^{3}$ Department of Pediatrics, \\ Harvard Medical School, Boston, MA, USA
}

Clustered regularly interspaced short palindromic repeats and CRISPR-associated protein 9 (CRISPR-Cas9) is an ancient prokaryotic defense system that precisely cuts foreign genomic DNA under the control of a small number of guide RNAs. The CRISPR-Cas9 system facilitates efficient double-stranded DNA cleavage that has been recently adopted for genome editing to create or correct inherited genetic mutations causing disease. Congenital heart disease (CHD) is generally caused by genetic mutations such as base substitutions, deletions, and insertions, which result in diverse developmental defects and remains a leading cause of birth defects. Pediatric CHD patients exhibit a spectrum of cardiac abnormalities such as septal defects, valvular defects, and abnormal chamber development. CHD onset occurs during the prenatal period and often results in early lethality during childhood. Because CRISPR-Cas9-based genome editing technology has gained considerable attention for its potential to prevent and treat diseases, we will review the CRISPR-Cas9 system as a genome editing tool and focus on its therapeutic application for $\mathrm{CHD}$.

Key words: CRISPR, Genome editing, Congenital heart diseases, Childhood onset

\section{Key message}

Clustered regularly interspaced short palindromic repeats and CRISPR-associated protein 9 (CRISPR-Cas9) system has made a big step in the genome editing which still requires technical developments for the efficient applications in the many fields including congenital heart diseases (CHDs), closely related to the genomic abnormality. In this review, we tried to cover the most updated researches of CRISPR-Cas9 in the CHDs to understand the current technologies, eventually becoming therapeutic bases for the $\mathrm{CHD}$ patients.

\section{Introduction}

Congenital heart disease (CHD) is the most commonly diag. nosed congenital disorder in newborns-accounting for the highest mortality rate outside of infectious etiologies. ${ }^{1)}$ Based on a 2017 survey of the regional, national, and global burden of CHD, these diseases account for 261, 247 deaths per year globally.2) Regionally, the highest annual mortality rate per 100,000 infants (i.e., $<1$ year old) was assigned to Oceania as estimated by the Cause of Death Ensembl model. Regardless of these national differences, $\mathrm{CHD}$ is a critical causative factor of childhood morbidity and mortality globally. ${ }^{3)}$

Substantial effort has been expended to understand pathogenesis of $\mathrm{CHD}$ by investigating genetic variations and molecular pathways. Many of these diseases have now been genetically characterized as a result of technological advancements. For example, aneuploidies (i.e., an abnormal number of chromosomes in cells $)^{4,5)}$ and microdeletions have been identified using fluorescence in situ hybridization to visualize chromosomal alterations. ${ }^{6-8)}$ Soon after these studies, single-base mutations were identified using human genomic data. Copy number variants ${ }^{9)}$ and single nucleotide polymorphisms ${ }^{10)}$ were subsequently discovered using recently developed high-throughput sequencing technologies. ${ }^{11)}$

Researchers have pursued countless means to develop, improve, and utilize genome editing strategies to alter genetic mutationinduced diseases, including CHD. These studies began with the discovery of restriction enzymes to create double-strand breaks (DSBs) that allow for genome editing. Several early methods employed zinc-finger nucleases (ZFNs) and transcription activator-like effector nucleases (TALENs) to improve the efficiency of editing ${ }^{12)}$; however, the discovery of the prokaryotic clustered regularly interspaced short palindromic repeats (CRISPR)Cas system revolutionized these efforts, as it was more specific, simple, and robust. ${ }^{13)}$ Consequently, CRISPR-Cas strategies to repair genetic mutations through either nonhomologous end joining or homologous dependent repair with wild-type alleles have been tested for various diseases using model systems. ${ }^{14)}$

The CRISPR adaptive immune system and the associated RNA-guided Cas nuclease were discovered serendipitously. ${ }^{15-19)}$ Bacteria possessing less susceptibility to bacteriophage attack were found to have a high homology between a repeating region and the phage genome, which led to the idea that these 


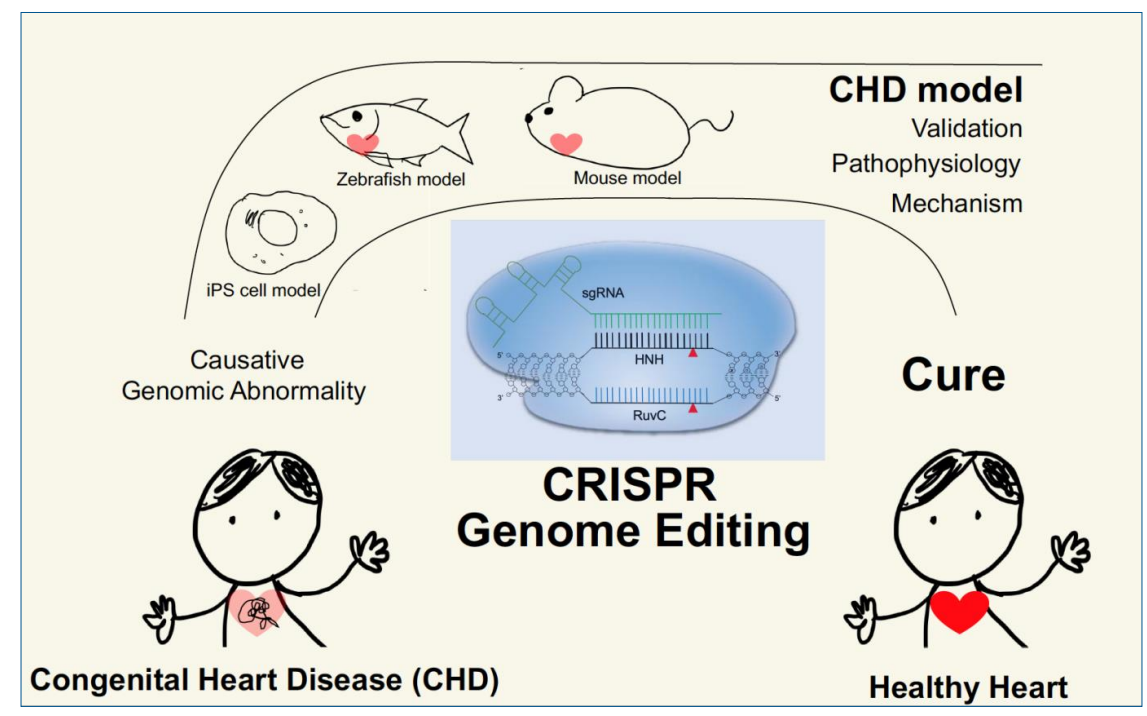

Graphical abstract.

sequences represented a bacterial defense mechanism. ${ }^{20)}$ In support of this suggestion, short phage genomic sequences, later called protospacers, ${ }^{21)}$ were found to be incorporated in the bacterial genome cluster. ${ }^{22)}$ These newly inserted sequences transcribed CRISPR RNAs (crRNAs), ${ }^{23-25)}$ which enabled Casmediated phage genomic cleavage with highly accurate target sequence specificity. ${ }^{25)}$ In addition to crRNAs, researchers identified additional RNAs necessary for CRISPR-Cas function, called transactivating crRNAs (tracrRNAs), ${ }^{23}$ ) which formed a secondary structure critical for recruiting the Cas protein to the phage genome. In addition to these RNA components, the targeting genome must contain a short recognition site named protospacer adjacent motif (PAM) ${ }^{26}$ ) which is proximally located and ranges from approximately 2 to 5 nucleotides from the targeting region. ${ }^{27,28)}$ It was determined that crRNAs and tracrRNAs became functional when they produced a single fused RNA called a single guide RNA (sgRNA). ${ }^{29)}$ These components were subsequently reconstituted in Escherichia coli ${ }^{29)}$ and eukaryotes. ${ }^{30,31)}$

More than 10 different CRISPR-Cas systems have been identified in bacteria and archaea. ${ }^{13,32,33)}$ Based on the Cas nuclease types and CRISPR sequences, these systems have been categorized into 2 classes. Class 1 contains type I, III, and IV CRISPR systems, which usually function in a multiple Cas protein complex. Class 2 contains type II, V, and VI CRISPR systems. $^{34,35)}$ In the latter type, a single DNA endonuclease called Cas9 is responsible for double-stranded DNA cleavage. Among these systems, the most prevalent is the type II CRISPRCas9 system, which was discovered in Streptococcus pyogenes. Its popularity results from the simplicity of the Cas9 enzyme (spCas9) and PAM motif (NGG) from this bacterium. ${ }^{36}$ )

In this review, we will focus on the CRISPR-spCas9 system to explain how it works, review applications using disease models, and discuss future research directions aimed at reducing mortality and improving the lives of children affected with CHD.

\section{CRISPR-Cas9 function}

The CRISPR-Cas9 system has similarities with RNA interference (RNAi). ${ }^{33,36)}$ Both are adaptive immune systems to defend against foreign organisms and both utilize RNA as a homologybased strategy to cleave nucleic acids. RNAi relies on 21 or 22 nucleotide double-stranded RNAs that mediate their activity through a family of endogenous ribonucleoprotein complexes called RNA-induced silencing complexes ${ }^{37,38)}$ that trigger target RNA degradation. ${ }^{39-41)}$ Similarly, CRISPR-Cas9 uses small RNAs by combining a crRNA and tracrRNA or using a fused sgRNA to recognize target sequences to produce a double-stranded break. Both RNAi, in the form of small interfering RNAs, and CRISPRCas9 are now widely used for both research and therapeutic applications.

The type II locus produces the Cas9 enzyme, which contains 6 functional domains. These domains have a multitude of functions, including binding of guide RNAs and target DNA sequences, interacting with the PAM motif, and cleaving nucleic acids. ${ }^{32,42,43)}$ The enzyme itself is 1368 amino acids in length and, based on structural studies, the $\mathrm{HNH}$-like nuclease domain and the RuvC domain share similarity with a retroviral integrase superfamily that employs a metal-ion catalytic mechanism that causes a conformational change to control enzymatic activity. 32,44) Based on this information, a conserved histidine (H840) residue in the $\mathrm{HNH}$-like domain and an aspartate (D10) residue (29) in the RuvC domain were established to be critical for cleavage. ${ }^{42,45)}$ Individual mutations of $\mathrm{H} 840 \mathrm{~A}$ or D10A cause Cas 9 to become a nicking endonuclease (nickase), which have only single-strand cleavage capabilities. Double mutants have no DNA cleavage ability and are referred to as dead Cas9 (dCas9). ${ }^{29)}$ Ordinarily, the $\mathrm{HNH}$-like domain cuts the target strand, which is complementary to the sgRNA, and the RuvC domain cuts the opposite, non-target DNA strand. ${ }^{42,46,47)}$ The C-terminal domain also interacts with the PAM motif in the target genome, ${ }^{26)}$ where 3 base pairs are excised to leave a blunt- 
ended molecule. ${ }^{29)}$ The crRNA and tracrRNA binding domains are critical for the exquisite positional genomic selectivity and the subsequent CRISPR-mediated interference.

Transcription of the CRISPR array locus and subsequent enzymatic processing of the precursor RNA (including RNase III-mediated cleavage and 5' end trimming) result in the generation of a mature crRNA that is approximately 20 nucleotides long. This crRNA contains the foreign nucleic acid recognition segment at the 5' end and CRISPR repeats at the 3' end. The latter target the protospacer region next to the PAM (NGG in case of CRISPR-Cas9). ${ }^{25)} \mathrm{A}$ small noncoding tracrRNA, which is transcribed from the CRISPR locus, can also associate with mature crRNA through CRISPR repeats to form a specific secondary structure that is necessary to recruit Cas9.23) The single sgRNA formed by crRNA and tracrRNA fusion has been the focus of efforts to optimize genome editing.29) A schematic representation of CRISPR-Cas9 cleavage is depicted in Fig. 1.

\section{Development of genome editing}

The CRISPR-Cas9 system is revolutionary because it permits genome editing of specific sequences by insertion, deletion, or substitution using rationally-designed templates. ${ }^{12,48)}$ Initial attempts to edit the genome used homologous recombination to insert exogenous foreign DNA ${ }^{49-51)}$; however, this process was inefficient and poorly controlled; resulting in random and multiple insertional events. ${ }^{51,52)}$ To find a more positiondependent strategy, researchers used restriction enzymes to target a particular locus to create a DSB. Unfortunately, enzymes that target short sequences (i.e., 4 to 6 nucleotides) ${ }^{53,54)}$ or long sequences (i.e., 14 to 40 nucleotides), ${ }^{55)}$ were limited by multiple target recognition sites and repair of DSBs by nonhomologous end joining. ${ }^{56)}$ As a result, researchers began to focus on engineering nucleases to allow greater positional specificity in editing the genome. A fusion protein using the zinc-finger module paired

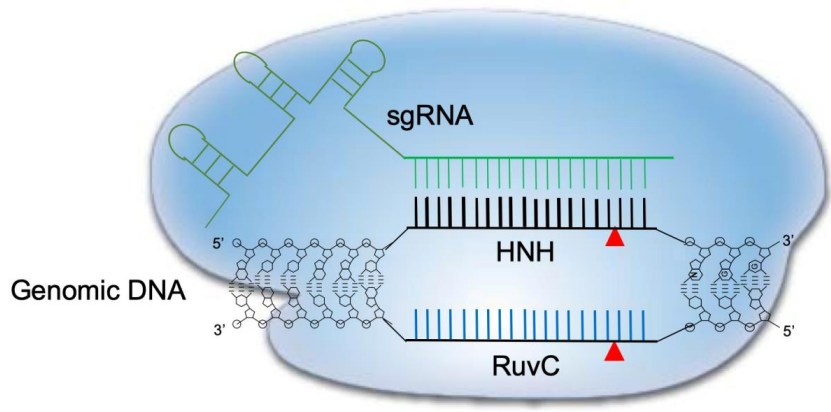

Fig. 1. Schematic diagram of CRISPR-Cas9 cleavage of double-stranded DNA. The Cas9 dependent protospacer adjacent motif (PAM) genomic sequence is NGG. A 20-nucleotide long sequence is targeted by a complementary RNA (sgRNA) and structural RNAs responsible for Cas9 enzyme recruitment. Once the sgRNA binds the target sequence, Cas9' s HNH-like endonuclease cuts the $3^{\prime}$ position end of the PAM motif. At the same time, the nontargeting genomic strand is cleaved by the RuvClike domain in Cas9, leading to a double-strand break. CRISPR-Cas9, clustered regularly interspaced short palindromic repeats and CRISPRassociated protein 9. with the DNA cleavage domain of the Fok1 endonuclease was developed and called ZFNs. These enzymes represented yet another step toward specific editing of DNA sequences. ${ }^{57-59)}$ The zinc-finger module could bind DNA by sensing a 3 base pair long stretch of DNA, which allowed precise positioning by combining different modules. ${ }^{60-62)}$ Around the same time, a bacterial transcription activator-like effector (TALE) was being used for a similar purpose. TALE bound DNA by sensing a single nucleotide. When recombined with the Fok1 endonuclease, the engineered TALEN enzyme was created, which also contributed to development of genome editing. ${ }^{63-66)}$ However, adoption of this technology was limited because every target DNA sequence required de novo molecular engineering of a chimeric protein. Consequently, the CRISPR-Cas9 system solved these issues as it relied on small, noncoding RNAs to exquisitely target specific sequences and it contained strong nuclease activity. ${ }^{48)}$

\section{Applications of CRISPR-Cas9 for CHD}

CHD is generally associated with genomic perturbations combined with environmental effects that often result in an unclear etiology. ${ }^{11)}$ Although genetic factors play important roles in CHD, detailed information is largely unknown. While, some of these genomic variations are not associated with a phenotype, those that are could benefit from genomic editing to cure CHD patients. The identification of causative genes and mutations in $\mathrm{CHDs}$ has accelerated with the recent development of next-generation sequencing technologies. A summary of selected causative CHD mutations in shown in Tables 1 and 2. Table 1 lists CHD phenotypes that have been considered for intervention using CRISPR-Cas9, while Table 2 lists potential mutations associated with CHDs that, if verified, may also benefit from a gene editing approach. Prior to implementation, the development and study of appropriate CHD models are necessary (Fig. 2). Below, we will focus on CRISPR-Cas9 applications using $\mathrm{CHD}$ animal models; however, there are many reviews of CRISPR-Cas9 strategies for human heart diseases. 14,67-69)

Initially, the development and testing of cardiac-specific CRISPR-Cas9 in vivo focused on mouse models. Carroll and colleagues developed transgenic mice expressing high levels of Cas9 in the heart using the $\alpha$-myosin heavy chain (Myh6) promoter combined with intraperitoneal injection of adenoassociated virus serotype 9 (AAV9) to deliver an sgRNA targeting Myh6. A single injection of this virus resulted in $75 \%$ transduction efficiency causing Myh6 repression. ${ }^{70)}$ Guo et al. ${ }^{71}$ utilized a Cre-LoxP genetic strategy for CRISPR-Cas9 delivery. Using the cardiac troponin $\mathrm{T}$ promoter to drive Cre enzyme expression with sgRNAs delivered using AAV9 in neonatal mice, a Cas9-GFP fusion protein incorporated in the Rosa26 locus guaranteed Cre activity-dependent Cas9 expression. With this strategy, cardiac troponin T-dependent gene editing by CRISPRCas9 was possible in neonatal mice. In addition, several genes 
Table 1. CRISPR-Cas9 in congenital heart diseases (CHDs)

\begin{tabular}{|c|c|c|c|c|c|c|}
\hline $\mathrm{CHD}$ & Causative gene (s) & Mutations & Cardiac anomalies & Model system & Cas9 & Ref. \\
\hline \multirow[t]{2}{*}{ DiGeorge syndrome } & DGCR2 & DGCR2 destroy & $\begin{array}{l}\text { IAA } \\
\text { PTA }\end{array}$ & Mouse TT2 ES cell & $\begin{array}{l}\text { NFL-hCas9; } \\
\text { sgRNA exon4 }\end{array}$ & 106 \\
\hline & $T B X 1$ & Knockout & $\begin{array}{l}\text { TOF } \\
\text { VSD }\end{array}$ & E14-Tg2a mESCs & $\begin{array}{l}\text { Alt-R } \\
\text { SpCas9 }\end{array}$ & 105 \\
\hline Barth syndrome & $T A Z$ & $328 \mathrm{~T}>\mathrm{C}$ & DCM & Human IPSC line & Cas9 & 100 \\
\hline $\begin{array}{l}\text { Wolff-Parkinson-White } \\
\text { syndrome }\end{array}$ & PRKAG2 & H530R & VT & Mouse & Cas9 & 79 \\
\hline \multirow{2}{*}{$\begin{array}{l}\text { Duchenne muscular } \\
\text { dystrophy }\end{array}$} & \multirow[t]{2}{*}{ Dystrophin } & \multirow{2}{*}{$\begin{array}{l}\text { Nonsense mutation } \\
\text { (exon 23) }\end{array}$} & \multirow[t]{2}{*}{ DCM } & Mouse, zygote & Cas9 mRNA & 82 \\
\hline & & & & Mouse & aav9-SaCas9 & 83 \\
\hline \multirow[t]{4}{*}{ Holt-Oram syndrome } & \multirow[t]{4}{*}{ TBX5 } & zTbx5b knockout & \multirow[t]{4}{*}{$\begin{array}{l}\text { ASD, AVSD, progressive } \\
\text { AV conduction disease }\end{array}$} & \multirow[t]{4}{*}{ Zebrafish } & \multirow[t]{4}{*}{$\begin{array}{l}\text { Cas9 mRNA } \\
\text { sgRNA }\end{array}$} & 91 \\
\hline & & $243-1 G>C$ & & & & 134 \\
\hline & & $148-1 G>C$ & & & & 135 \\
\hline & & S196ter, DGlu243Fter, R237W & & & & 87 \\
\hline \multirow[t]{5}{*}{ Heterotaxy syndrome } & \multirow[t]{2}{*}{ ZIC3 } & $890 G>T(C 297 F)$ & \multirow{5}{*}{$\begin{array}{c}\text { DILV, DORV, d-TGA, AVSD, } \\
\text { SA, TA, TGA, PA, VSD, } \\
\text { PDA, LSVC }\end{array}$} & & & 93 \\
\hline & & $\begin{array}{c}\text { 680dup } \\
\text { 842_843del } \\
\text { 869del } \\
1063 \mathrm{G}>\mathrm{T} \\
1111 \mathrm{~A}>\mathrm{C} \\
1060+1 \mathrm{G}>\mathrm{A}\end{array}$ & & Zebrafish mutation & & 96 \\
\hline & DNAH10 & 12q24.31 3-duplicate & & Zebrafish knockout & zCas9 mRNA & 97 \\
\hline & RNF115 & 1q21.11-deletion & & Zebrafish knockout & zCas9 mRNA & 97 \\
\hline & CFC1 & R78W, R112C, R189C, G174del1 & & mouse, zebrafish & & 136 \\
\hline \multirow[t]{7}{*}{ Noonan syndrome } & \multirow[t]{3}{*}{ PTPN11 } & $\begin{array}{c}922 A>G, c .923 A>G \\
(\text { exon 8) }\end{array}$ & \multirow[t]{6}{*}{$\begin{array}{l}\text { PVS } \\
\text { HCM }\end{array}$} & \multirow{7}{*}{ iPSC } & \multirow{7}{*}{ Cas9 } & 137 \\
\hline & & exon $2,3,4,7,8,13$ & & & & 138 \\
\hline & & T59A & & & & 139 \\
\hline & LZTR1 & Intronic & & & & 103 \\
\hline & KRAS & $458 \mathrm{~A}>\mathrm{T}$ & & & & 140 \\
\hline & RAF1 & S259T & & & & 139 \\
\hline & SOS1 & K170E & $\begin{array}{c}\text { delayed psychomotor } \\
\text { development }\end{array}$ & & & 139 \\
\hline \multirow[t]{5}{*}{ Marfan syndrome } & FBN1 & 4282 delC 7_8insTC 2192 delC & $A o D, A D, M V P$ & \multirow{3}{*}{ Human embryo } & \multirow{5}{*}{ BE3 } & 141 \\
\hline & & T7498C & & & & 125 \\
\hline & FBLN4 & 1189G >A (exon 11) & & & & 142 \\
\hline & TGFBR2 & W521RR528H R537P & & Zebrafish & & 143 \\
\hline & TGFBR1 & $973+1 G>A$ 806-2A $>C$ (exon5) & & & & 144 \\
\hline \multirow[t]{5}{*}{ Nonsyndromic } & GATA4 & G296S & ASD, VSD & iPSC & spCas9 (H840A) & 109 \\
\hline & MyHC6 & R443P & HLHS & iPSC & Cas9 & 123 \\
\hline & NKX2.5 & A119S & LVNC & iPSC & Cas9 & 111 \\
\hline & MYH7 & L387F & LVNC & iPSC & Cas9 & 111 \\
\hline & MKL2 & $\mathrm{Q670H}$ & LVNC & iPSC & Cas9 & 111 \\
\hline
\end{tabular}

CRISPR-Cas9, clustered regularly interspaced short palindromic repeats and CRISPR-associated protein 9; AD, aortic root dissection; AoD, aortic root dilation; ASD, atrial septal defect; AVSD, atrioventricular septal defect; BE3, base editing 3; BI, bronchial inversus; BRB, bilateral right bronchi (short); BSVC, bilateral superior vena cava; CAVC, complete atrioventricular canal; CCD, cardiac conduction disease; D, dextrocardia; d-TGA, D-transposition of the great vessels; DCM, dilated cardiomyopathy; DILV, double inlet left ventricle; DOLV, double-outlet left ventricle; DORV, double-outlet right ventricle; dup duplication; del deletion; HCM, hypertrophic cardiomyopathy; HLHS, hypoplastic left heart syndrome; iPSCs, induced pluripotent stem cells; IQR, interquartile range; IRAA, isomerism of right atrial appendages; LAA, left aortic arch; LCS, liver centrally situated; LSL, left-sided liver; LSS, left-sided stomach; LSVC, left superior vena cava, LVNC, left ventricular noncompaction cardiomyopathy; MVP, mitral valve prolapse; PA pulmonary atresia; PAVC, partial atrioventricular canal; PDA, patent ductus arteriosus; PLSVC, persistent left superior vena cava; PS, pulmonary stenosis; PTA, persistent truncus arteriosus; PVS, pulmonary valve stenosis; RAA, right aortic arch; RSS, right-sided stomach; SA, single atrium; SIV, superior-inferior ventricle; SV, single ventricle; TA, tricuspid atresia; TGA, transposition of the great arteries; TGA/MGA, translocation of great arteries/malposition of great arteries; TOF, tetralogy of Fallot; TPAVD, total anomalous pulmonary venous drainage; VSD, ventricle septum defect; IAA, interrupted aortic arch; VT, ventricular tachyarrhythmia.

reported to be commonly associated with CHDs (e.g., Myh and serum response factor) were targeted to develop an animal model and to study the pathogenesis of disease. ${ }^{72)}$

Later studies used human induced pluripotent stem cells
(hiPSCs) $)^{73-75)}$ as model systems, which may enable a personalized medical approach to treat CHD patients. With the power of CRISPR-Cas9, hiPSC-based models containing mutations corresponding to those identified in patients have begun to clarify 
Table 2. Potential candidates for CRISPR-Cas9 genome editing

\begin{tabular}{|c|c|c|c|c|c|c|}
\hline $\mathrm{CHD}$ & Causative gene(s) & Mutations & Cardiac anomalies & Model system & Cas9 & Ref. \\
\hline \multirow[t]{2}{*}{ Costello syndrome } & \multirow[t]{2}{*}{ HRAS } & c.35G>C (exon2) & PS, HCM, CCD & & N/A & 145 \\
\hline & & Gly13Cys (exon2) & $\mathrm{VT}, \mathrm{HCM}$ & & N/A & 146 \\
\hline \multirow[t]{4}{*}{ LEOPARD syndrome } & PTPN11 & $\begin{array}{l}\text { Tyr279Cys, Tyr279Ser, Ala461Thr, Gly464Ala, } \\
\text { Thr468Met, Arg498Trp, Gln506Pro, Gln510Glu }\end{array}$ & \multirow[t]{4}{*}{ HCM, PS, CCD } & & N/A & 147 \\
\hline & RAF1 & Ser257Leu Leu613Val & & & N/A & 147 \\
\hline & $B R A F$ & Thr241Pro Leu245Phe & & & N/A & 148 \\
\hline & RAF1 & exon $7,14,11$ & & & N/A & 127 \\
\hline \multirow[t]{3}{*}{ Alagille syndrome } & $J A G 1$ & 2026delT 2071T>A, 2078G>A 2091G>A & \multirow{3}{*}{$\begin{array}{c}\text { PS, TOF, ASD, } \\
\text { peripheral } \\
\text { pulmonary } \\
\text { stenosis }\end{array}$} & \multirow{3}{*}{ H268Q Jag1+/Ndr mice } & N/A & 149 \\
\hline & & $\mathrm{H} 268 \mathrm{Q}$ & & & N/A & 150 \\
\hline & NOTCH2 & c.5930 1G>A (exon33), c.1331G>A (exon8) & & & N/A & 151 \\
\hline Nonsyndromic & MyHC6 & $\begin{array}{c}3835 C>T, 18429 T->A, 4164 C>A, \\
4395 C>A, 5661 G>A\end{array}$ & ASD, HCM & & N/A & $\begin{array}{l}119, \\
121\end{array}$ \\
\hline
\end{tabular}

CRISPR-Cas9, clustered regularly interspaced short palindromic repeats and CRISPR-associated protein 9; CHD, congenital heart disease; PS, pulmonary stenosis; HCM, hypertrophic cardiomyopathy; CCD, cardiac conduction disease; LEOPARD, Lentigines, Electrocardiographic defect, Ocular hypertelorism, Pulmonary stenosis, Abnormalities of the genitalia, Retarded growth and Deafness; VT, ventricular tachyarrhythmia; TOF, tetralogy of Fallot; ASD, atrial septal defect; N/A, not available

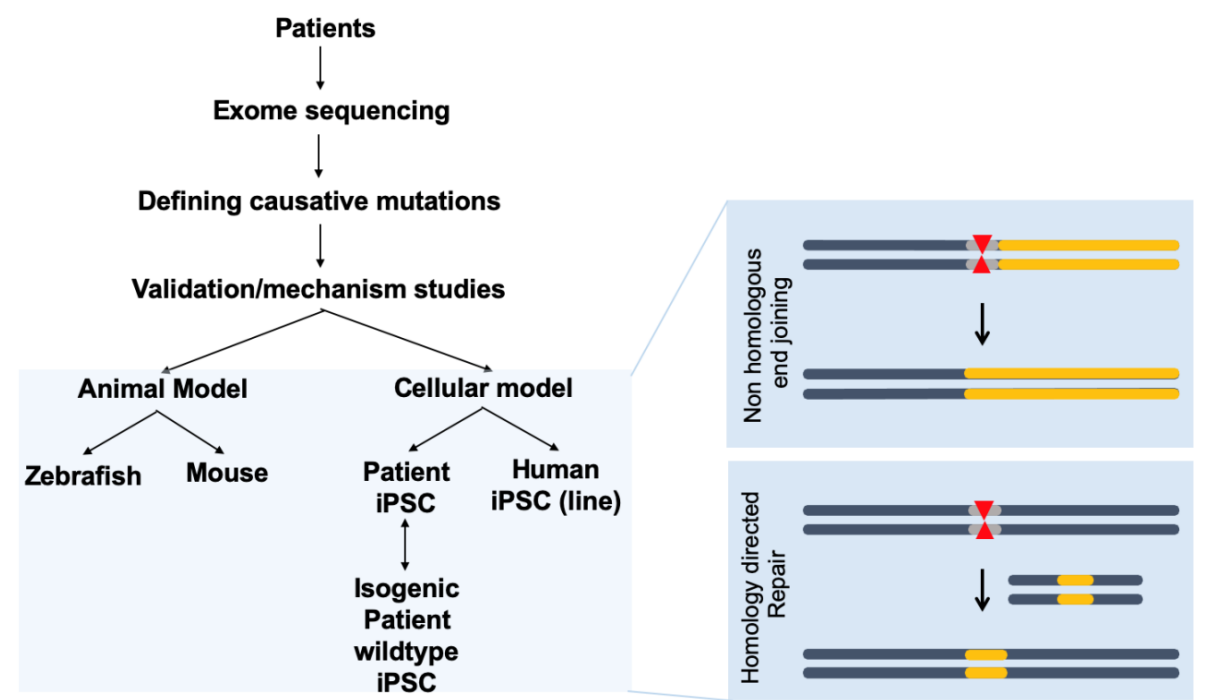

Fig. 2. CRISPR-Cas9 applications for human congenital heart disease (CHD). Human samples such as white blood cells can be used for exome sequencing to detect novel genetic variations with single nucleotide resolution. Identification of novel mutations causing $\mathrm{CHD}$ can be validated in animal models such as mice or zebrafish, which are amenable to genetic manipulation. Application of CRISPR-Cas editing in both animal models and in vitro systems, such as induced pluripotent stem cells (iPSCs) or differentiated cells derived from iPSCs, can validate the editing design. CRISPR-Cas9, clustered regularly interspaced short palindromic repeats and CRISPR-associated protein 9.

the mechanisms underlying the pathogenesis of these diseases. In addition, mutations in cells derived from patients can be corrected using CRISPR-Cas9-mediated homology directed repair (HDR). ${ }^{76}$ The advantage of utilizing iPS cells edited by CRISPR-Cas9 is that they can be easily sequenced to confirm genomic editing and identify off-target effects.

\section{Wolff-Parkinson-White syndrome}

Wolff-Parkinson-White (WPW) patients suffer from cardiomyopathy due to ventricular pre-excitation, hypertrophy, ventricular tachyarrhythmia, heart failure, and sudden death. The onset of this syndrome can occur at any age, including in utero and early childhood. ${ }^{77,78)}$ Xie et al. ${ }^{79)}$ identified a novel mutation in the gene encoding Protein Kinase AMP-Activated
Non-Catalytic Subunit Gamma 2 (PRKAG2) in familial WPW syndrome patients. Several mutations of this gene, which is responsible for AMP-activated protein kinase sensing of energy and nutrition, have shown to cause WPW syndrome. The authors identified a H530R missense mutation and confirmed this finding by establishing both transgenic and knock-in mice model that had abnormal cardiac electrical activity, ventricular hypertrophy, and excessive glycogen deposition. They subsequently applied an AAV9 mediated Cas9 and sgRNA delivery strategy to target the mutated PRKAG2 allele in their knock-in mice (+/H530R). A single intravenous injection of mixed AAV9 particles at postnatal day 4 successfully disrupted the mutant allele to restore left ventricular wall thickness and glycogen deposition. Consequently, they developed a potential CRISPR- 
Cas9 therapeutic strategy for WPW syndrome patients. ${ }^{79}$

\section{Duchenne muscular dystrophy}

Duchenne muscular dystrophy (DMD) is an $\mathrm{x}$-linked disease caused by mutations in the dystrophin gene, which is composed of 79 exons. This disease leads to progressive muscular weakness and severe cardiomyopathy. ${ }^{80,81)}$ Despite advancements in the care for DMD patients, there is no therapy that can reverse the course of this disease. The $m d x$ mouse model of DMD $\left(\mathrm{C} 57 \mathrm{BL} / 10 \mathrm{ScSn}-\mathrm{Dm} d^{m d x} / \mathrm{J}\right)$ contains a nonsense mutation in exon 23. Long and colleagues used a CRISPR-Cas9 strategy to correct this mutation. ${ }^{82)}$ They injected a Cas9 mRNA/sgRNA/ ssODN (single-stranded oligodeoxynucleotide) template for HDR into mouse zygotes in the germ line to potentially correct this mutation in every cell. The authors examined 11 CRISPRCas 9 corrected mice and 7 mice were confirmed to have a successful mutation correction via HDR. This strategy resulted in a mosaic correction ranging from $2 \%$ to $100 \%$. The authors confirmed that the CRISPR-Cas9-mediated correction in $m d x$ mice recovered from the DMD phenotype using histological analyses and serum creatine kinase measurements. ${ }^{82}$ Because genome editing of a germ line condition is not currently feasible in humans, the authors presented an efficient delivery strategy for somatic cell correction of DMD mutations. Furthermore, El Refaey et al. ${ }^{83)}$ used another DMD mouse model (i.e., mdx/ Utrp+/-) with AAV9-mediated systemic delivery of the Staphylococcus aureus Cas9/sgRNA for genome editing in the heart. In this study, approximately $40 \%$ of dystrophin expression was established in cardiomyocytes, which reduced cardiac fibrosis and improved contractility.

\section{Holt-Oram syndrome}

Holt-Oram syndrome is a rare congenital disease characterized by anterior pre-axial limb abnormalities and defective cardiac development, including septal defects. ${ }^{84-86)}$ The TBX5 gene has several mutational hotspots and is believed to be a causative gene in this syndrome. ${ }^{87,88)}$ At least 14 mutations (including null mutations and missense mutations) in human patients have been reported. ${ }^{84)}$ Using Zebrafish as a genetic model system, the importance of $t b x 5$ during cardiogenesis has been shown in the heartstring knockout, which have a linear heart tube that fails to loop-mirroring developmental defects in human Holt-Oram syndrome. ${ }^{89)}$ Because of a gene duplication in this species, Zebrafish have 2 forms of $t b \times 5$, called $a$ and $b$. Morpholino oligomers ${ }^{90}$ ) were constructed to validate the observations from the heartstring and CRISPR/Cas9 knockout fish at the molecular and phenotypic levels. These experiments confirmed the vital importance of these genes in cardiogenesis. For the CRISPR/Cas9 knockout fish, the authors designed a sgRNA that targeted the start codon of $t b x 5 b$ with Cas 9 mRNAs, which was injected at the embryonic one-cell stage to create the F0 tbx5b knockout. ${ }^{91)}$ These fish showed alterations in somite size, vasculature cell differentiation, and subsequent trunk blood vessel patterning.

\section{Heterotaxy syndrome}

Heterotaxy syndrome is characterized by the left-right asymmetry defects that can affect the heart. ${ }^{92)}$ ZIC3, DNAH10, $R N F 15$, and CFC1, have been reported as potentially causative genes. ZIC3 is a zinc-finger transcription factor belonging to the Gli superfamily that is located at the Xq26.2 chromosomal position. ${ }^{93)}$ Mutations in ZIC3 are associated with about $75 \%$ of $x$-linked, familial Heterotaxy syndrome patients with transposition of the great arteries and double-outlet right ventricles. ${ }^{11)}$ ZIC3 hypomorphic mice, ${ }^{94)}$ Xenopus, and zebrafish models have been developed to validate the function of ZIC3 during early cardiogenesi ${ }^{95,96)}$; however, there are currently no reports of CRISPR/Cas9 studies of this gene.

In addition to ZIC3, duplications of the DNAH10 gene located at 12q24.31 appear to be involved in Heterotaxy syndrome. DNAH1O is expressed in the cilia and the protein from this gene is a component of the inner dynein arm that connects to microtubules to enable flagellar motility in protozoans. The generation of CRISPR-Cas9-mediated dnah10 mutants in zebrafish (F0) showed cardiac defects reminiscent of Heterotaxy syndrome. ${ }^{97)}$ This study provided the first in vivo and functional evidence for dnah10 in left/right patterning. At the same time, the authors expanded the number of causative gene candidates for this syndrome by identifying RNF115 deletion mutations using CRISPR-Cas9.

\section{CAKUTHED syndrome}

A similar study was performed for the pre-B cell leukemia factor 1 (PBX1) gene mutation, which has been identified as a potentially causative gene in the Congenital Anomalies of Kidney and Urinary Tract Syndrome with or without Hearing Loss, Abnormal Ears, or Developmental Delay (CAKUTHED). Mutation of this transcription factor is associated with CAKUTHED combined with CHD. Alankarage et al. identified a novel missense mutation (R184P) in tetralogy of Fallot ${ }^{98)}$ patients. ${ }^{99)}$ To understand of this PBX1 mutation, the authors generated knockin animals using CRISPR-Cas9. These mice have some of the same developmental defects observed in CAKUTHED, such as a ventricular septal defect (VSD). ${ }^{99)}$

\section{Barth syndrome}

Wang et al. ${ }^{100)}$ developed a hiPSC-based model of Barth syndrome. Mutations in the taffazzin (TAZ) gene can cause this syndrome, which is characterized by weakened cardiac muscle leading to dilated cardiomyopathy in male infants. ${ }^{100,101)}$ The authors discovered a mutation (T328C) in TAZ and established a cell model using 2 independent methods. In the first, the authors used hiPSC-derived cardiomyocytes (iPSC-CM) from a Barth syndrome patient. These cells were used to correct the T328C mutation using CRISPR-Cas9. In addition, the authors engineered the same mutation in a human iPSC line (PGP1iPSC) by CRISPR-Cas 9 targeting of exon 6 of TAZ. These independent cell models had a similar cellular phenotype to Barth syndrome patients, including abnormal cardiolipin biogenesis 
and mitochondrial function. ${ }^{100)}$ This research was followed up with a study using a mouse TAZ knockout mouse model and AAV9-mediated rescue to support the idea that $T A Z$ is a critical target for the treatment of Barth syndrome. ${ }^{102)}$

\section{Noonan syndrome}

Mutations in the leucine zipper-like transcription regulator 1 (LZTR1) have been reported to cause the most common symptom of Noonan Syndrome-hypertrophic cardiomyopathy. ${ }^{103)}$ Noonan syndrome patients often suffer from pulmonary valvular stenosis, atrial and ventricular septal defects, in addition to hypertrophic cardiomyopathy and early disease onset. ${ }^{104)}$ Using hiPSCs to confirm phenotypic cardiomyopathy, an intronic mutation in LZTR1 was found to create a stop codon in the next exon. The CRISPR-Cas9 correction of this mutation restored expression of wild-type LZTR1. ${ }^{103)}$

\section{DiGeorge syndrome}

DiGeorge syndrome is caused by a microdeletion of 22q11.2. This syndrome is characterized by developmental defects that include cardiovascular malformations. ${ }^{6-8)}$ Approximately 30 to 40 genes are deleted in DiGeorge syndrome. As a result, several causative genes have been studied. In particular, Tbx1 deletion induces haplo-insufficiency and cardiac defects similar to those observed in DiGeorge syndrome. CRISPR-Cas9 knockout of Tbx1 in murine stem cells (E14-Tg2a) enabled chromatin remodeling studies and transcriptome analyses to understand the pathogenesis of this syndrome. ${ }^{105)}$ Similarly, the putative adhesion receptor protein DGCR2, which has shown muscular defects as well as the risk for developing schizophrenia in DiGeorge syndrome, was deleted in mouse TT2 embryonic stem cells using CRISPR-Cas9 to validate and confirm the role of this protein in these processes. ${ }^{106-108)}$

\section{Other CHD-related mutations}

In nonsyndromic human $\mathrm{CHD}$, several transcriptional factors are known to be required for proper cardiovascular development. Mutations in GATA4, TBX5, and MyH6/7 have repeatedly been reported as causative for $\mathrm{CHD}$. For example, GATA4 mutations were identified in septal defects and conduction abnormalities. ${ }^{109,110)}$ Ang and colleagues developed a patient-specific, iPSC-based model from dermal fibroblasts to investigate one of these mutations. These authors also used CRISPR-Cas9 to correct the G296S mutation of GATA4. ${ }^{109 \text { ) }}$

Gifford and colleagues performed exome sequencing of a 2-month-old infant with congestive heart failure with left ventricular noncompaction cardiomyopathy (LVNC) ${ }^{111)}$ which results from incomplete cardiomyocyte maturation and accounts for up to $10 \%$ of cardiomyopathies. ${ }^{112)}$ Three mutations were identified (i.e., A119S in NKX2-5, Q670H in MKL2, and L387F in $M y H 7 .{ }^{111)}$ NKX2-5 governs cardiomyocyte development. 113-115) MLK2 is important in the epithelial-to-mesenchymal transition during embryonic development, ${ }^{16,117)}$ and $\mathrm{MyH7}$ encodes a crucial contractile protein. These mutations were confirmed in mice using CRISPR-Cas9 to create triple-heterozygous mice $\left(\mathrm{Mkl} 2^{\mathrm{Q} 664 \mathrm{H} /+} \mathrm{Myh} 7^{\mathrm{L} 387 \mathrm{~F} /+} \mathrm{Nkx2}-5^{\mathrm{A} 118 \mathrm{~S} /+}\right)$, which recapitulated the LVNC phenotype. In addition, human fibroblast-derived hiPSCs harboring the same 3 mutations showed abnormal cardiomyocyte aggregation; thereby, supporting the claim that these 3 mutations are important in the pathogenesis of LVNC. ${ }^{111)}$

At the same time, MyH6 mutations can cause hypertrophic or dilated cardiomyopathy (HCM or DCM, respectively) and atrial septal defect (ASD). ${ }^{118)}$ ASD type III (sinus venosus atrial septal defect) is also associated with MyHC6 mutations. ${ }^{119)}$ For instance, whole exome sequencing of 2 patients with $\mathrm{CHD}$ revealed a $\mathrm{MyH} 6$ mutation that caused truncation of $\alpha$-myosin heavy chain protein that is implicated in ASD type III. ${ }^{120)}$ In addition, several other $\mathrm{MyH} 6$ mutations associated with $\mathrm{CHD}$ (mainly ASDs) have been confirmed using gain-of-function studies in the $\mathrm{C} 2 \mathrm{C} 12$ cell line. ${ }^{121)}$ In the case of one $\mathrm{MyH} 6$ mutation (R443P) identified in a family with hypoplastic left heart syndrome, ${ }^{122)}$ patient-derived hiPSCs were used in combination with CRISPR-Cas9 to demonstrate phenotypicallydefective cardiomyocytes. ${ }^{123)}$

While all connective tissues can be affected Marfan syndrome, the most serious complication involves the heart. Mitral valve prolapse and aortic aneurysm are commonly associated with this syndrome, which results from mutations in the connective tissue scaffold protein, fibrillin-1 (FBN1). ${ }^{124)}$ Correction of one of these mutations (T7498C) was tested using base editing 3 (BE3). ${ }^{125)}$ Another example is LEOPARD (an acronym for Lentigines, Electrocardiographic defect, Ocular hypertelorism, Pulmonary stenosis, Abnormalities of the genitalia, Retarded growth and Deafness; and Noonan Syndrome with multiple lentigines) syndrome, which is a rare congenital disease with cardiac defects such as ventricular hypertrophy, cardiomyopathy, and abnormal electrical conduction. ${ }^{126-128)}$ As more mutations are identified in CHD patients, ${ }^{11)}$ the possibility of utilizing CRISPR-Cas to correct these disease-causing mutations may soon be possible.

\section{Conclusions}

CRISPR-Cas9 is a versatile and robust tool for genome editing. The first clinical trial of this technology was launched in 2019 and is called the BRILLIANCE trial by Allergan (Dublin, Ireland) and Editas Medicine (Cambridge, MA, USA). This phase 1 and 2 trial uses CRISPR-Cas editing to restore vision in patients with Leber's congenital amaurosis 10 (LCA10), which is caused by a point mutation in the CEP290 gene. ${ }^{129,130)}$ This trial relies in direct injection into the eye, near the photoreceptor cells, rather than systemic delivery or genome editing of cells removed from the body for subsequent replacement.

The application of CRISPR-Cas-mediated genome editing in humans requires very careful consideration, given that DSB is likely irreversible and certainly leads to genetic instability. The latter consequence has been shown in cancers and off-target 
DNA cleavage. ${ }^{60,131)}$ As a result, any genome editing would need to be both precise and efficient to ensure safety. In addition, patients would need to be closely monitored for immune reactions because of the bacterial origins of Cas enzymes are generally infectious in humans. ${ }^{34)}$ The relatively recent germline application of CRISPR-Cas9 editing in human pre-implantation embryos showed efficient genome editing with endogenous, germline-specific DNA repair to correct a paternal allele mutation in the MYBPC3, which causes cardiomyopathy. ${ }^{132)}$ Despite this success, many concerns remain; especially in regard to reproducibility for other heterozygous mutations and offtarget DSBs.

In view of these concerns, somatic cell application of CRISPRCas is a safer choice, despite the challenge presented by inefficient Cas deliver to these cells. Modified AAVs are an attractive alternative; however, these viruses can be immunogenic and the most commonly used Cas9 protein from $S$. pyogenes, is above the packaging size limit for AAVs. ${ }^{133)}$ As a result, researchers continue to engineer and/or identify smaller versions of spCas9. While the promise of this technology cannot be disputed, Dr. Fyodor Urnov from the University of California, Berkeley, commented following the BRILLIANCE clinical trial that the "... technical challenges, and inherent safety concerns, are much greater." Therefore, further studies will be required prior to application of gene editing in patients with $\mathrm{CHD}$.

\section{Conflicts of interest}

No potential conflict of interest relevant to this article was reported.

\section{Acknowledgments}

This work is supported by NRF-2020R1A2C1013377, NRF2017R1D1A1B03030852 for H Seok and HL149401 from $\mathrm{NIH}$ to DZ Wang. We thank members of the Wang Laboratory for their careful reading and comments.

\section{ORCID}

Heeyoung Seok @ https://orcid.org/0000-0003-2699-9935

Douglas B. Cowan 1 https://orcid.org/0000-0002-6309-2737

Da-Zhi Wang $@$ https://orcid.org/0000-0003-1774-6549

\section{References}

1. Hoffman JI, Kaplan S. The incidence of congenital heart disease. J Am Coll Cardiol 2002;39:1890-900.

2. Collaborators GBDCHD. Global, regional, and national burden of congenital heart disease, 1990-2017: a systematic analysis for the Global Burden of Disease Study 2017. Lancet Child Adolesc Health 2020;4:185200.

3. Bruneau BG. The developmental genetics of congenital heart disease. Nature 2008;451:943-8.

4. Scambler PJ. The 22q11 deletion syndromes. Hum Mol Genet 2000; 9:2421-6.

5. Ewart AK, Morris CA, Atkinson D, Jin W, Sternes K, Spallone P, et al. Hemizygosity at the elastin locus in a developmental disorder, Williams syndrome. Nat Genet 1993;5:11-6.
6. Moerman P, Goddeeris P, Lauwerijns J, Van der Hauwaert LG. Cardiovascular malformations in DiGeorge syndrome (congenital absence of hypoplasia of the thymus). Br Heart J 1980;44:452-9.

7. Lindsay EA, Botta A, Jurecic V, Carattini-Rivera S, Cheah YC, Rosenblatt $\mathrm{HM}$, et al. Congenital heart disease in mice deficient for the DiGeorge syndrome region. Nature 1999;401:379-83.

8. Oda T, Elkahloun AG, Pike BL, Okajima K, Krantz ID, Genin A, et al. Mutations in the human Jagged1 gene are responsible for Alagille syndrome. Nat Genet 1997;16:235-42.

9. Redon R, Ishikawa S, Fitch KR, Feuk L, Perry GH, Andrews TD, et al. Global variation in copy number in the human genome. Nature 2006;444:444-54.

10. International HapMap C. The International HapMap Project. Nature 2003;426:789-96.

11. Richards AA, Garg V. Genetics of congenital heart disease. Curr Cardiol Rev 2010;6:91-7.

12. Gaj T, Gersbach CA, Barbas CF 3rd. ZFN, TALEN, and CRISPR/Casbased methods for genome engineering. Trends Biotechnol 2013;31:397405 .

13. Wiedenheft B, Sternberg SH, Doudna JA. RNA-guided genetic silencing systems in bacteria and archaea. Nature 2012;482:331-8.

14. van Kampen SJ, van Rooij E. CRISPR craze to transform cardiac biology. Trends Mol Med 2019;25:791-802.

15. Li B, Niu Y, Ji W, Dong Y. Strategies for the CRISPR-based therapeutics. Trends Pharmacol Sci 2020;41:55-65.

16. Mojica FJ, Juez G, Rodriguez-Valera F. Transcription at different salinities of Haloferax mediterranei sequences adjacent to partially modified PstI sites. Mol Microbiol 1993;9:613-21.

17. Ishino Y, Shinagawa H, Makino K, Amemura M, Nakata A. Nucleotide sequence of the iap gene, responsible for alkaline phosphatase isozyme conversion in Escherichia coli, and identification of the gene product. J Bacteriol 1987;169:5429-33.

18. Mojica FJM, Montoliu L. On the origin of CRISPR-Cas technology: from prokaryotes to mammals. Trends Microbiol 2016;24:811-20.

19. Brussow H. Phages of dairy bacteria. Annu Rev Microbiol 2001;55:283303.

20. Makarova KS, Grishin NV, Shabalina SA, Wolf YI, Koonin EV. A putative RNA-interference-based immune system in prokaryotes: computational analysis of the predicted enzymatic machinery, functional analogies with eukaryotic RNAi, and hypothetical mechanisms of action. Biol Direct 2006;1:7.

21. Jackson SA, McKenzie RE, Fagerlund RD, Kieper SN, Fineran PC, Brouns SJ. CRISPR-Cas: adapting to change. Science 2017;356:eaal5056.

22. Barrangou R, Fremaux C, Deveau H, Richards M, Boyaval P, Moineau S, et al. CRISPR provides acquired resistance against viruses in prokaryotes. Science 2007;315:1709-12.

23. Deltcheva E, Chylinski K, Sharma CM, Gonzales K, Chao Y, Pirzada ZA, et al. CRISPR RNA maturation by trans-encoded small RNA and host factor RNase III. Nature 2011;471:602-7.

24. Barrangou R. Diversity of CRISPR-Cas immune systems and molecular machines. Genome Biol 2015;16:247.

25. Brouns SJ, Jore MM, Lundgren M, Westra ER, Slijkhuis RJ, Snijders AP, et al. Small CRISPR RNAs guide antiviral defense in prokaryotes. Science 2008;321:960-4.

26. Anders C, Niewoehner O, Duerst A, Jinek M. Structural basis of PAMdependent target DNA recognition by the Cas9 endonuclease. Nature 2014;513:569-73.

27. Westra ER, van Houte S, Gandon S, Whitaker R. The ecology and evolution of microbial CRISPR-Cas adaptive immune systems. Philos Trans R Soc Lond B Biol Sci 2019;374:20190101.

28. Mojica FJM, Diez-Villasenor C, Garcia-Martinez J, Almendros C. Short motif sequences determine the targets of the prokaryotic CRISPR defence system. Microbiology (Reading) 2009;155(Pt 3):733-40.

29. Jinek M, Chylinski K, Fonfara I, Hauer M, Doudna JA, Charpentier E. A programmable dual-RNA-guided DNA endonuclease in adaptive bacterial immunity. Science 2012;337:816-21.

30. Mali P, Yang L, Esvelt KM, Aach J, Guell M, DiCarlo JE, et al. RNA- 
guided human genome engineering via Cas9. Science 2013;339:823-6.

31. Cong L, Ran FA, Cox D, Lin S, Barretto R, Habib N, et al. Multiplex genome engineering using CRISPR/Cas systems. Science 2013;339:81923.

32. Jiang F, Doudna JA. CRISPR-Cas9 structures and mechanisms. Annu Rev Biophys 2017;46:505-29.

33. Bhaya D, Davison M, Barrangou R. CRISPR-Cas systems in bacteria and archaea: versatile small RNAs for adaptive defense and regulation. Annu Rev Genet 2011;45:273-97.

34. Koonin EV, Makarova KS, Zhang F. Diversity, classification and evolution of CRISPR-Cas systems. Curr Opin Microbiol 2017;37:67-78.

35. Wright AV, Nunez JK, Doudna JA. Biology and applications of CRISPR systems: Harnessing Nature's toolbox for genome engineering. Cell 2016;164:29-44.

36. Leenay RT, Maksimchuk KR, Slotkowski RA, Agrawal RN, Gomaa AA, Briner $\mathrm{AE}$, et al. Identifying and visualizing functional PAM diversity across CRISPR-Cas systems. Mol Cell 2016;62:137-47.

37. Tomari Y, Matranga C, Haley B, Martinez N, Zamore PD. A protein sensor for siRNA asymmetry. Science 2004;306:1377-80.

38. Rand TA, Petersen S, Du F, Wang X. Argonaute2 cleaves the anti-guide strand of siRNA during RISC activation. Cell 2005;123:621-9.

39. Fire A, Xu S, Montgomery MK, Kostas SA, Driver SE, Mello CC. Potent and specific genetic interference by double-stranded RNA in Caenorhabditis elegans. Nature 1998;391:806-11.

40. Bernstein E, Caudy AA, Hammond SM, Hannon GJ. Role for a bidentate ribonuclease in the initiation step of RNA interference. Nature 2001;409:363-6.

41. Macrae IJ, Zhou K, Li F, Repic A, Brooks AN, Cande WZ, et al. Structural basis for double-stranded RNA processing by Dicer. Science 2006;311:195-8.

42. Gasiunas G, Barrangou R, Horvath P, Siksnys V. Cas9-crRNA ribonucleoprotein complex mediates specific DNA cleavage for adaptive immunity in bacteria. Proc Natl Acad Sci US A 2012;109:E2579-86.

43. Heler R, Samai P, Modell JW, Weiner C, Goldberg GW, Bikard D, et al. Cas9 specifies functional viral targets during CRISPR-Cas adaptation. Nature 2015;519:199-202.

44. Nishimasu H, Ran FA, Hsu PD, Konermann S, Shehata SI, Dohmae N, et al. Crystal structure of Cas9 in complex with guide RNA and target DNA. Cell 2014;156:935-49.

45. Garneau JE, Dupuis ME, Villion M, Romero DA, Barrangou R, Boyaval $\mathrm{P}$, et al. The CRISPR/Cas bacterial immune system cleaves bacteriophage and plasmid DNA. Nature 2010;468:67-71.

46. Chen H, Choi J, Bailey S. Cut site selection by the two nuclease domains of the Cas9 RNA-guided endonuclease. J Biol Chem 2014;289:1328494.

47. Hale CR, Zhao P, Olson S, Duff MO, Graveley BR, Wells L, et al. RNAguided RNA cleavage by a CRISPR RNA-Cas protein complex. Cell 2009;139:945-56.

48. Adli M. The CRISPR tool kit for genome editing and beyond. Nat Commun 2018;9:1911.

49. Smithies O, Gregg RG, Boggs SS, Koralewski MA, Kucherlapati RS. Insertion of DNA sequences into the human chromosomal beta-globin locus by homologous recombination. Nature 1985;317:230-4.

50. Thomas KR, Folger KR, Capecchi MR. High frequency targeting of genes to specific sites in the mammalian genome. Cell 1986;44:419-28.

51. Capecchi MR. Altering the genome by homologous recombination. Science 1989;244:1288-92.

52. Lin FL, Sperle K, Sternberg N. Recombination in mouse L cells between DNA introduced into cells and homologous chromosomal sequences. Proc Natl Acad Sci US A 1985;82:1391-5.

53. Smith HO, Wilcox KW. A restriction enzyme from Hemophilus influenzae. I. Purification and general properties. J Mol Biol 1970;51:379-91.

54. Kelly TJ Jr, Smith HO. A restriction enzyme from Hemophilus influenzae. II. J Mol Biol 1970;51:393-409.

55. Rouet P, Smih F, Jasin M. Introduction of double-strand breaks into the genome of mouse cells by expression of a rare-cutting endonuclease. Mol Cell Biol 1994;14:8096-106.
56. Jeggo PA. DNA breakage and repair. Adv Genet 1998;38:185-218.

57. Klug A, Rhodes D. Zinc fingers: a novel protein fold for nucleic acid recognition. Cold Spring Harb Symp Quant Biol 1987;52:473-82.

58. Kim YG, Cha J, Chandrasegaran S. Hybrid restriction enzymes: zinc finger fusions to Fok I cleavage domain. Proc Natl Acad Sci U S A 1996; 93:1156-60.

59. Bibikova M, Carroll D, Segal DJ, Trautman JK, Smith J, Kim YG, et al. Stimulation of homologous recombination through targeted cleavage by chimeric nucleases. Mol Cell Biol 2001;21:289-97.

60. Porteus $\mathrm{MH}$, Baltimore D. Chimeric nucleases stimulate gene targeting in human cells. Science 2003;300:763.

61. Urnov FD, Miller JC, Lee YL, Beausejour CM, Rock JM, Augustus S, et al. Highly efficient endogenous human gene correction using designed zincfinger nucleases. Nature 2005;435:646-51.

62. Miller JC, Holmes MC, Wang J, Guschin DY, Lee YL, Rupniewski I, et al. An improved zinc-finger nuclease architecture for highly specific genome editing. Nat Biotechnol 2007;25:778-85.

63. Boch J, Scholze H, Schornack S, Landgraf A, Hahn S, Kay S, et al. Breaking the code of DNA binding specificity of TAL-type III effectors. Science 2009;326:1509-12.

64. Moscou MJ, Bogdanove AJ. A simple cipher governs DNA recognition by TAL effectors. Science 2009;326:1501.

65. Zhang F, Cong L, Lodato S, Kosuri S, Church GM, Arlotta P. Efficient construction of sequence-specific TAL effectors for modulating mammalian transcription. Nat Biotechnol 2011;29:149-53.

66. Miller JC, Tan S, Qiao G, Barlow KA, Wang J, Xia DF, et al. A TALE nuclease architecture for efficient genome editing. Nat Biotechnol 2011; 29:143-8.

67. Motta BM, Pramstaller PP, Hicks AA, Rossini A. The impact of CRISPR/ Cas9 technology on cardiac research: from disease modelling to therapeutic approaches. Stem Cells Int 2017;2017:8960236.

68. Vermersch E, Jouve C, Hulot JS. CRISPR/Cas9 gene-editing strategies in cardiovascular cells. Cardiovasc Res 2020;116:894-907.

69. Nguyen Q, Lim KRQ, Yokota T. Genome editing for the understanding and treatment of inherited cardiomyopathies. Int J Mol Sci 2020;21:733.

70. Carroll KJ, Makarewich CA, McAnally J, Anderson DM, Zentilin L, Liu N, et al. A mouse model for adult cardiac-specific gene deletion with CRISPR/Cas9. Proc Natl Acad Sci US A 2016;113:338-43.

71. Guo Y, VanDusen NJ, Zhang L, Gu W, Sethi I, Guatimosim S, et al. Analysis of cardiac myocyte maturation using CASAAV, a platform for rapid dissection of cardiac myocyte gene function in vivo. Circ Res 2017; 120:1874-88.

72. Guo Y, Jardin BD, Zhou P, Sethi I, Akerberg BN, Toepfer CN, et al. Hierarchical and stage-specific regulation of murine cardiomyocyte maturation by serum response factor. Nat Commun 2018;9:3837.

73. Ogasawara T, Shiba Y. iPS cells as a source of cardiac regeneration. Nihon Rinsho 2016;74 Suppl 6:287-92.

74. Rikhtegar R, Pezeshkian M, Dolati S, Safaie N, Afrasiabi Rad A, Mahdipour M, et al. Stem cells as therapy for heart disease: iPSCs, ESCs, CSCs, and skeletal myoblasts. Biomed Pharmacother 2019;109:304-13.

75. Martins AM, Vunjak-Novakovic G, Reis RL. The current status of iPS cells in cardiac research and their potential for tissue engineering and regenerative medicine. Stem Cell Rev Rep 2014;10:177-90.

76. Porteus M. Genome editing: a new approach to human therapeutics. Annu Rev Pharmacol Toxicol 2016;56:163-90.

77. Olen MM, Baysa SJ, Rossi A, Kanter RJ, Fishberger SB. Wolff-ParkinsonWhite Syndrome: a stepwise deterioration to sudden death. Circulation 2016;133:105-6.

78. Munger TM, Packer DL, Hammill SC, Feldman BJ, Bailey KR, Ballard DJ, et al. A population study of the natural history of Wolff-ParkinsonWhite syndrome in Olmsted County, Minnesota, 1953-1989. Circulation 1993;87:866-73.

79. Xie C, Zhang YP, Song L, Luo J, Qi W, Hu J, et al. Genome editing with CRISPR/Cas9 in postnatal mice corrects PRKAG2 cardiac syndrome. Cell Res 2016;26:1099-111.

80. Hoffman EP, Brown RH Jr, Kunkel LM. Dystrophin: the protein product of the Duchenne muscular dystrophy locus. Cell 1987;51:919-28. 
81. Verhaart IEC, Aartsma-Rus A. Therapeutic developments for Duchenne muscular dystrophy. Nat Rev Neurol 2019;15:373-86.

82. Long C, McAnally JR, Shelton JM, Mireault AA, Bassel-Duby R, Olson EN. Prevention of muscular dystrophy in mice by CRISPR/Cas9mediated editing of germline DNA. Science 2014;345:1184-8.

83. El Refaey M, Xu L, Gao Y, Canan BD, Adesanya TMA, Warner SC, et al. In vivo genome editing restores dystrophin expression and cardiac function in dystrophic mice. Circ Res 2017;121:923-9.

84. Basson CT, Bachinsky DR, Lin RC, Levi T, Elkins JA, Soults J, et al. Mutations in human TBX5 [corrected] cause limb and cardiac malformation in Holt-Oram syndrome. Nat Genet 1997;15:30-5.

85. Smith AT, Sack GH Jr, Taylor GJ. Holt-Oram syndrome. J Pediatr 1979; 95:538-43.

86. Basson CT, Cowley GS, Solomon SD, Weissman B, Poznanski AK, Traill TA, et al. The clinical and genetic spectrum of the Holt-Oram syndrome (heart-hand syndrome). N Engl J Med 1994;330:885-91.

87. Basson CT, Huang T, Lin RC, Bachinsky DR, Weremowicz S, Vaglio A, et al. Different TBX5 interactions in heart and limb defined by Holt-Oram syndrome mutations. Proc Natl Acad Sci US A 1999;96:2919-24.

88. Vanlerberghe C, Jourdain AS, Ghoumid J, Frenois F, Mezel A, Vaksmann G, et al. Holt-Oram syndrome: clinical and molecular description of 78 patients with TBX5 variants. Eur J Hum Genet 2019;27:360-8.

89. Garrity DM, Childs S, Fishman MC. The heartstrings mutation in zebrafish causes heart/fin Tbx5 deficiency syndrome. Development 2002;129:4635-45.

90. Stainier DYR, Raz E, Lawson ND, Ekker SC, Burdine RD, Eisen JS, et al. Guidelines for morpholino use in zebrafish. PLoS Genet 2017;13: e1007000.

91. Boyle Anderson EAT, Ho RK. A transcriptomics analysis of the Tbx5 paralogues in zebrafish. PLoS One 2018;13:e0208766.

92. Zhu L, Belmont JW, Ware SM. Genetics of human heterotaxias. Eur J Hum Genet 2006;14:17-25.

93. Li S, Liu S, Chen W, Yuan Y, Gu R, Song Y, et al. A novel ZIC3 gene mutation identified in patients with heterotaxy and congenital heart disease. Sci Rep 2018;8:12386.

94. Haaning AM, Quinn ME, Ware SM. Heterotaxy-spectrum heart defects in Zic3 hypomorphic mice. Pediatr Res 2013;74:494-502.

95. Houtmeyers R, Souopgui J, Tejpar S, Arkell R. The ZIC gene family encodes multi-functional proteins essential for patterning and morphogenesis. Cell Mol Life Sci 2013;70:3791-811.

96. Paulussen AD, Steyls A, Vanoevelen J, van Tienen FH, Krapels IP, Claes GR, et al. Rare novel variants in the ZIC3 gene cause X-linked heterotaxy. Eur J Hum Genet 2016;24:1783-91.

97. Liu C, Cao R, Xu Y, Li T, Li F, Chen S, et al. Rare copy number variants analysis identifies novel candidate genes in heterotaxy syndrome patients with congenital heart defects. Genome Med 2018;10:40.

98. van der Ven JPG, van den Bosch E, Bogers A, Helbing WA. Current outcomes and treatment of tetralogy of Fallot. F1000Res 2019;8:F1000 Faculty Rev-1530.

99. Alankarage D, Szot JO, Pachter N, Slavotinek A, Selleri L, Shieh JT, et al. Functional characterization of a novel PBX1 de novo missense variant identified in a patient with syndromic congenital heart disease. Hum Mol Genet 2020;29:1068-82.

100. Wang G, McCain ML, Yang L, He A, Pasqualini FS, Agarwal A, et al. Modeling the mitochondrial cardiomyopathy of Barth syndrome with induced pluripotent stem cell and heart-on-chip technologies. Nat Med 2014;20:616-23.

101. Spencer CT, Bryant RM, Day J, Gonzalez IL, Colan SD, Thompson WR, et al. Cardiac and clinical phenotype in Barth syndrome. Pediatrics 2006;118:e337-46.

102. Wang S, Li Y, Xu Y, Ma Q, Lin Z, Schlame M, et al. AAV gene therapy prevents and reverses heart failure in a murine knockout model of barth syndrome. Circ Res 2020;126:1024-39.

103. Hanses U, Kleinsorge M, Roos L, Yigit G, Li Y, Barbarics B, et al. Intronic CRISPR repair in a preclinical model of noonan syndrome-associated cardiomyopathy. Circulation 2020;142:1059-76.

104. Pierpont ME, Digilio MC. Cardiovascular disease in Noonan syndrome.
Curr Opin Pediatr 2018;30:601-8.

105. Cirino A, Aurigemma I, Franzese M, Lania G, Righelli D, Ferrentino R, et al. Chromatin and transcriptional response to loss of TBX1 in early differentiation of mouse cells. Front Cell Dev Biol 2020;8:571501.

106. Watanabe S, Sakurai T, Nakamura S, Miyoshi K, Sato M. The combinational use of CRISPR/Cas9 and targeted toxin technology enables efficient isolation of bi-allelic knockout non-human mammalian clones. Int J Mol Sci 2018;19:1075.

107. Molinard-Chenu A, Dayer A. The candidate schizophrenia risk gene DGCR2 regulates early steps of corticogenesis. Biol Psychiatry 2018; 83:692-706.

108. Mugikura SI, Katoh A, Watanabe S, Kimura M, Kajiwara K. Abnormal gait, reduced locomotor activity and impaired motor coordination in Dgcr2-deficient mice. Biochem Biophys Rep 2016;5:120-6.

109. Garg V, Kathiriya IS, Barnes R, Schluterman MK, King IN, Butler CA, et al. GATA4 mutations cause human congenital heart defects and reveal an interaction with TBX5. Nature 2003;424:443-7.

110. Hirayama-Yamada K, Kamisago M, Akimoto K, Aotsuka H, Nakamura $\mathrm{Y}$, Tomita $\mathrm{H}$, et al. Phenotypes with GATA4 or NKX2.5 mutations in familial atrial septal defect. Am J Med Genet A 2005;135:47-52.

111. Gifford CA, Ranade SS, Samarakoon R, Salunga HT, de Soysa TY, Huang Y, et al. Oligogenic inheritance of a human heart disease involving a genetic modifier. Science 2019;364:865-70.

112. Finsterer J, Stollberger C, Towbin JA. Left ventricular noncompaction cardiomyopathy: cardiac, neuromuscular, and genetic factors. Nat Rev Cardiol 2017;14:224-37.

113. Schott JJ, Benson DW, Basson CT, Pease W, Silberbach GM, Moak JP, et al. Congenital heart disease caused by mutations in the transcription factor NKX2-5. Science 1998;281:108-11.

114. Lyons I, Parsons LM, Hartley L, Li R, Andrews JE, Robb L, et al. Myogenic and morphogenetic defects in the heart tubes of murine embryos lacking the homeo box gene Nkx2-5. Genes Dev 1995;9:165466.

115. Carniel E, Taylor MR, Sinagra G, Di Lenarda A, Ku L, Fain PR, et al. Alpha-myosin heavy chain: a sarcomeric gene associated with dilated and hypertrophic phenotypes of cardiomyopathy. Circulation 2005;112:549.

116. Trembley MA, Velasquez LS, de Mesy Bentley KL, Small EM. Myocardin-related transcription factors control the motility of epicardiumderived cells and the maturation of coronary vessels. Development 2015; 142:21-30.

117. Posch MG, Waldmuller S, Muller M, Scheffold T, Fournier D, AndradeNavarro MA, et al. Cardiac alpha-myosin (MYH6) is the predominant sarcomeric disease gene for familial atrial septal defects. PLoS One 2011;6:e28872.

118. Nyboe C, Olsen MS, Nielsen-Kudsk JE, Hjortdal VE. Atrial fibrillation and stroke in adult patients with atrial septal defect and the long-term effect of closure. Heart 2015;101:706-11.

119. Ching YH, Ghosh TK, Cross SJ, Packham EA, Honeyman L, Loughna $\mathrm{S}$, et al. Mutation in myosin heavy chain 6 causes atrial septal defect. Nat Genet 2005;37:423-8.

120. Razmara E, Garshasbi M. Whole-exome sequencing identifies R1279X of MYH6 gene to be associated with congenital heart disease. BMC Cardiovasc Disord 2018;18:137.

121. Granados-Riveron JT, Ghosh TK, Pope M, Bu'Lock F, Thornborough $\mathrm{C}$, Eason J, et al. Alpha-cardiac myosin heavy chain (MYH6) mutations affecting myofibril formation are associated with congenital heart defects. Hum Mol Genet 2010;19:4007-16.

122. Theis JL, Zimmermann MT, Evans JM, Eckloff BW, Wieben ED, Qureshi MY, et al. Recessive MYH6 mutations in hypoplastic left heart with reduced ejection fraction. Circ Cardiovasc Genet 2015;8:564-71.

123. Tomita-Mitchell A, Stamm KD, Mahnke DK, Kim MS, Hidestrand PM, Liang HL, et al. Impact of MYH6 variants in hypoplastic left heart syndrome. Physiol Genomics 2016;48:912-21.

124. Dietz HC, Cutting GR, Pyeritz RE, Maslen CL, Sakai LY, Corson GM, et al. Marfan syndrome caused by a recurrent de novo missense mutation in the fibrillin gene. Nature 1991;352:337-9. 
125. Zeng Y, Li J, Li G, Huang S, Yu W, Zhang Y, et al. Correction of the Marfan syndrome pathogenic FBN1 mutation by base editing in human cells and heterozygous embryos. Mol Ther 2018;26:2631-7.

126. Tartaglia M, Mehler EL, Goldberg R, Zampino G, Brunner HG, Kremer $\mathrm{H}$, et al. Mutations in PTPN11, encoding the protein tyrosine phosphatase SHP-2, cause Noonan syndrome. Nat Genet 2001;29:465-8.

127. Pandit B, Sarkozy A, Pennacchio LA, Carta C, Oishi K, Martinelli S, et al. Gain-of-function RAF1 mutations cause Noonan and LEOPARD syndromes with hypertrophic cardiomyopathy. Nat Genet 2007;39: 1007-12.

128. Lee KJ, Choi H, Choi WH, Kwon SU, Doh JH, Namgung J, et al. The management of cardiovascular abnormalities in patient with LEOPARD syndrome. Korean Circ J2010;40:339-42.

129. Ledford H. CRISPR treatment inserted directly into the body for first time. Nature 2020;579:185.

130. Maeder ML, Stefanidakis M, Wilson CJ, Baral R, Barrera LA, Bounoutas GS, et al. Development of a gene-editing approach to restore vision loss in Leber congenital amaurosis type 10. Nat Med 2019;25:229-33.

131. Weinstock DM, Richardson CA, Elliott B, Jasin M. Modeling oncogenic translocations: distinct roles for double-strand break repair pathways in translocation formation in mammalian cells. DNA Repair (Amst) 2006;5:1065-74.

132. Ma H, Marti-Gutierrez N, Park SW, Wu J, Lee Y, Suzuki K, et al. Correction of a pathogenic gene mutation in human embryos. Nature 2017;548:413-9.

133. Baltimore D, Berg P, Botchan M, Carroll D, Charo RA, Church G, et al. Biotechnology. A prudent path forward for genomic engineering and germline gene modification. Science 2015;348:36-8.

134. Rios-Serna LJ, Diaz-Ordonez L, Candelo E, Pachajoa H. A novel de novo TBX5 mutation in a patient with Holt-Oram syndrome. Appl Clin Genet 2018;11:157-62.

135. Guo Q, Shen J, Liu Y, Pu T, Sun K, Chen S. Exome sequencing identifies a c.148-1G $>$ C mutation of TBX5 in a Holt-Oram family with unusual genotype-phenotype correlations. Cell Physiol Biochem 2015;37:106674.

136. Bamford RN, Roessler E, Burdine RD, Saplakoglu U, dela Cruz J, Splitt $\mathrm{M}$, et al. Loss-of-function mutations in the EGF-CFC gene CFC1 are associated with human left-right laterality defects. Nat Genet 2000;26: 365-9.

137. Athota JP, Bhat M, Nampoothiri S, Gowrishankar K, Narayanachar SG, Puttamallesh V, et al. Molecular and clinical studies in 107 Noonan syndrome affected individuals with PTPN11 mutations. BMC Med Genet 2020;21:50.

138. Tartaglia M, Kalidas K, Shaw A, Song X, Musat DL, van der Burgt I, et al. PTPN11 mutations in Noonan syndrome: molecular spectrum, genotype-phenotype correlation, and phenotypic heterogeneity. Am J Hum Genet 2002;70:1555-63.
139. Ko JM, Kim JM, Kim GH, Yoo HW. PTPN11, SOS1, KRAS, and RAF1 gene analysis, and genotype-phenotype correlation in Korean patients with Noonan syndrome. J Hum Genet 2008;53:999-1006.

140. Kim J, Cho SY, Yang A, Jang JH, Choi Y, Lee JE, et al. An atypical case of Noonan syndrome with KRAS mutation diagnosed by targeted exome sequencing. Ann Pediatr Endocrinol Metab 2017;22:203-7.

141. Wang Y, Li X, Li R, Yang Y, Du J. Identification of novel causal FBN1 mutations in pedigrees of Marfan syndrome. Int J Genomics 2018;2018:1246516.

142. Sulu A, Baspinar O, Sahin DA. Giant aortic aneurysm due to fibulin- 4 deficiency: case series. Turk Pediatri Ars 2019;54:119-24.

143. Lin J, Vora M, Kane NS, Gleason RJ, Padgett RW. Human Marfan and Marfan-like Syndrome associated mutations lead to altered trafficking of the type II TGFbeta receptor in Caenorhabditis elegans. PLoS One 2019;14:e216628.

144. Fujiwara T, Takeda N, Hara H, Morita H, Kishihara J, Inuzuka R, et al. Distinct variants affecting differential splicing of TGFBR1 exon 5 cause either Loeys-Dietz syndrome or multiple self-healing squamous epithelioma. Eur J Hum Genet 2018;26:1151-8.

145. Gripp KW, Lin AE. Costello syndrome: a Ras/mitogen activated protein kinase pathway syndrome (rasopathy) resulting from HRAS germline mutations. Genet Med 2012;14:285-92.

146. Gripp KW, Hopkins E, Sol-Church K, Stabley DL, Axelrad ME, Doyle D, et al. Phenotypic analysis of individuals with Costello syndrome due to HRAS p.G13C. Am J Med Genet A 2011;155A:706-16.

147. Martinez-Quintana E, Rodriguez-Gonzalez F. LEOPARD syndrome: clinical features and gene mutations. Mol Syndromol 2012;3:145-57.

148. Sarkozy A, Carta C, Moretti S, Zampino G, Digilio MC, Pantaleoni $\mathrm{F}$, et al. Germline BRAF mutations in Noonan, LEOPARD, and cardiofaciocutaneous syndromes: molecular diversity and associated phenotypic spectrum. Hum Mutat 2009;30:695-702.

149. Fischetto R, Palmieri VV, Tripaldi ME, Gaeta A, Michelucci A, Delvecchio M, et al. Alagille syndrome: a Novel mutation in JAG1 gene. Front Pediatr 2019;7:199.

150. Andersson ER, Chivukula IV, Hankeova S, Sjoqvist M, Tsoi YL, Ramskold D, et al. Mouse model of alagille syndrome and mechanisms of Jagged1 missense mutations. Gastroenterology 2018;154:1080-95.

151. McDaniell R, Warthen DM, Sanchez-Lara PA, Pai A, Krantz ID, Piccoli $\mathrm{DA}$, et al. NOTCH2 mutations cause Alagille syndrome, a heterogeneous disorder of the notch signaling pathway. Am J Hum Genet 2006;79:16973 .

How to cite this article: Seok H, Deng R, Cowan DB, Wang DZ. Application of CRISPR-Cas9 gene editing for congenital heart disease Clin Exp Pediatr 2021;64:269-79. https://doi. org/10.3345/cep.2020.02096 